\title{
Performance Evaluation of Geological Disaster Relief Operations in China using SBM-DEA Methodology
}

pengfei bai ( $\sim$ baipengfei@cueb.edu.cn )

CUEB: Capital University of Economics and Business

ruifang La

China University of Petroleum

Qianqian Duan

Beijing Wuzi University

\section{Research Article}

Keywords: Geological disasters, Rescue efficiency, SBM model, Redundancy

Posted Date: August 18th, 2021

DOI: https://doi.org/10.21203/rs.3.rs-716616/v1

License: (c) (i) This work is licensed under a Creative Commons Attribution 4.0 International License.

Read Full License 


\title{
${ }^{1}$ Performance evaluation of geological disaster relief operations in \\ China using SBM-DEA methodology
}

\author{
Pengfei Bai ${ }^{1}$, Ruifang $\mathrm{La}^{2}$, and Qianqian Duan ${ }^{3}$ \\ ${ }^{1}$ School of Management and Engineering, Capital University of Economics and \\ Business, Beijing 100070, China \\ 2School of Economics and Management, China University of Petroleum Qingdao, \\ Shandong 266580, China \\ 3 School of logistics, Beijing Wuzi University, Beijing 101149, China
}

\begin{abstract}
Geological disasters have caused enormous damage to human beings and the economy in China. Chinese government pay great effort on geological disaster relief. Usually, the efficiency of the disaster rescue is the first priority to be considered. Takeing the historical analysis of China's geological disaster rescue as the main line , in this paper, we developed a slacks-based measure data envelopment analysis (SBMDEA) model to evaluate the performance of 18 geological disasters relief during 20152019 in China, which are used to examine the performance of the geological disasters rescue activities. The results show that though the capabilities of geo-disaster relief is continuous improvement from 2015 to 2019, China's geological disasters rescue system is still at the primary stage. Especially, the efficiency of landslide rescue operation is pretty low. We analysis the factors influencing the efficiency and provide several suggestions for capacity improvement of geo-disasters rescue.
\end{abstract}

Key words: Geological disasters; Rescue efficiency; SBM model; Redundancy

\section{Introduction}

China is an geological disaster-prone country, China has one of the most serious geological disaster damage statistics and casualty rates in the world. According to Emergency Events Database (EM-DAT) statistics, during 2008-2018, 150 thousand geological disasters took place and caused more than 7000 casualties. There are more than 280 thousand potential geological hazards which thread about 15 million people ${ }^{[1]}$. so the Chinese government pay great effort on the prevention and rescue of the geological disaster ${ }^{[2]}$.

Tremendous progress has been made in response to many challenges resulting from geo-disaster. However, geo-disaster rescue is complicated, and great emphasis should 
be placed on its efficiency to achieve the best results. Chinese government can mobilize the whole country to deal with the great disaster and make maximum efforts to reduce casualties. Meanwhile, several disaster relief operations show that China are experiencing an increasing number of overreaction problem in disaster relief $\mathrm{f}^{[3]}$. Recent case show that there are more rescue teams and heavy machineries deployed than the requirement at the scene of the disaster, which is a waste of rescue resource and caused relief. Under the premise of ensuring rescue resource supply, the rescue efficiency should be improved. The performance evaluation of the geological disasters rescue operations should be conducted, and lessons should be learned to improve the rescue performance.

The objective of this paper is to develop a benchmarking framework for geological disaster rescue operations. The remaining parts of the paper are as follow. Section 2 summarize some literature on disaster rescue performance. Section 3 presents the SBMDEA method and history data for evaluating the geo-disaster rescue performance. Section 4 presents the empirical results and policy implications. Conclusions are given in Section 5.

\section{2. literature review}

The traditional method of disaster relief performance analysis is usually to set the factors of search and rescue, medical rescue, transportation recovery, logistics supply and emergency evacuation, and get the comprehensive index by its calculation of its index ${ }^{[5]}$ weighting method. However, this method is sensitive to the selection of the weights of each sub-index, and the weighting method is subjective, which affects the analysis results.

Data envelopment analysis (DEA) is a well-known method for measuring efficiency among decision making units (DMUs).More than 40 years ago, Charnes et al ${ }^{[6]}$ proposed the CCR model that allows for the translation of fractional linear measures of efficiency into a linear programming model.DEA exists because of its 
unique ability to measure the efficiency of multiple-input and multiple-output DMUs without the need to assign weights to inputs and outputs in advance different DEA models ${ }^{[7], ~[8]}$.DEA has applications in many fields including education ${ }^{[9]}$, banking ${ }^{[10],}$ ${ }^{[11]}$, manufacturing ${ }^{[12]}$, and others ${ }^{[13-17]}$.

DEA can be used as a decision analysis tool in several fields because it does not focus on finding universal relationships among all units evaluated in the sample.DEA allows each unit in the data to have its own production function and then assesses the efficiency of that single unit by comparing it with the efficiency of other units ${ }^{[18]}$.

A large number of studies on the efficiency of disaster response are based on earthquake, hurricane and flood disasters, mainly on humanitarian organizations and medical institutions. Research on geological disasters has focused on process documentation ${ }^{[19]}$, causal mechanisms ${ }^{\text {[20], [21], risk and loss assessment }}{ }^{\text {[22]-[24] }}$, disaster prediction ${ }^{[25]}$, stabilization and remedial measures- ${ }^{[26]}$, etc., of landslides and mudflows, and qualitative analysis of factors influencing disaster relief efficiency and suggestions for improvement of relief efficiency.

Current research findings on disaster response efficiency include three main areas: First, the analysis of factors affecting rescue efficiency. It mainly includes the rescue process, methods and different roles in disaster events, the impact of information and communication networks ${ }^{[27]}$, the location of supplies and post-disaster relief funds ${ }^{[28]}$ and the geographical location of the affected country ${ }^{[29]}$ on the rescue efficiency; Wei J (2016) studied the impact of economic, political, cultural, geographical location and disaster type on the rescue efficiency based on the perspective of emergency supply chain ${ }^{[30]}$; Gao L explored the disaster relief capacity of Heilongjiang province in the context of government input in the past decade to study the factors affecting the relief capacity $^{[31]}$.

Second, from the resource allocation perspective. Acimovic J (2016) established a two-stage stochastic optimization model based on actual material stockpile data to evaluate the relief response capability of disaster relief agencies in the United States ${ }^{[32]}$. 
Taking the "Wenchuan earthquake" as an example, Sun Huali (2019) introduced a timeliness evaluation function to evaluate the execution efficiency of key links by considering the relationship between the amount of medical resources invested and the rescue work efficiency, and proved the existence of an optimal value for the same resource ratio through theoretical derivation ${ }^{[33]}$.

Third, from the relief supply chain perspective. Zobel C (2016) used the DEA method to evaluate relief efficiency by building an input-output matrix and considered data envelopment analysis and dynamic frontier analysis as the two most important methods ${ }^{[34]}$. Abidi H (2014) ${ }^{[35]}$ and Blecken A (2010) ${ }^{[36]}$ pointed out that the evaluation of humanitarian relief efficiency is very lacking, and Schulz S (2009) proposed principles for selecting evaluation indicators for the efficiency of the post-disaster logistics operations of the International Red Cross and Red Crescent ${ }^{[37]}$. Üstün A (2015) used the DEA method to evaluate the efficiency of humanitarian organizations' disaster relief in the 1999 earthquake in Turkey ${ }^{[38]}$, and Guan G (2016) used the Wenchuan earthquake as an example of efficiency performance in terms of analyzed the synergy of the rescue supply chain ${ }^{[39]}$, Leng Q (2018) used DEA-SBM model to calculate the efficiency of 86 natural disaster rescues by international organizations during 20012017, and Tobit regression was used to analyze the influencing factors ${ }^{[40]}$. Lin W (2019) constructed an ArcGIS-based maritime rescue efficiency evaluation model from calculated the maritime rescue efficiency of Japan and Korea in specific sea areas of the Middle East Sea ${ }^{[41]}$. Expert scholars have made some progress in exploring the efficiency of disaster relief using DEA models ${ }^{[42], ~[43] . ~}$

Combined with the existing research results, the following research aspects still need to be improved: (1) Most of the research scope of geological hazards is focused on earthquake hazards, while there is little research on landslide and debris flow hazards. (2) In geological disaster rescue, it is important to improve rescue efficiency by evaluating the inputs and outputs of rescue efficiency, constructing a rescue efficiency evaluation index system, and finding out the relationship between disaster procedures 
and rescue inputs. (3) There is a lack of research results and relevant case data on the evaluation of rescue efficiency of major geological disasters, and the research on rescue efficiency is mainly based on a single disaster or a single organization, which needs to effectively improve the efficiency of disaster relief.

This paper analyzes the "input-output" indexes of 18 major geological disaster rescue cases of landslides and mudslides that occurred in China from 2015-2019, and constructs a rescue efficiency evaluation model based on the "rescue-disaster" index, conducted a study of geological disaster rescue efficiency.

\section{Methodology and Data Collection}

\subsection{Slacks-based measure of efficiency (SBM) DEA model}

DEA includes both radial and non-radial models. The radial model is represented by the CCR (Charnes-Cooper-Rhodes) model ${ }^{[44]}$. The treatment results respond to the changes in the input or output ratio. However, not all inputs (outputs) are scaled in the actual modeling. It ignores the slack variables and the efficiency may be overestimated.

Non-radial DEA methods can overcome such limitations, such as SBM, the SBM model proposed by Tone (2001) (see also Pastor et al., 1999) ${ }^{[45]}$. It has three variations: input, output and non-oriented, and the un-oriented model has to have both input and output orientations. Following, the SBM model is introduced to estimate geological disaster rescue operation efficiency ${ }^{[46]}$.

$$
\rho=\min \frac{1-\frac{1}{m} \sum_{i=1}^{m} \frac{s_{i}^{-}}{x_{i o}}}{1+\frac{1}{q_{1}+q_{2}}\left(\sum_{r=1}^{q_{1}} \frac{s_{r}^{+}}{y_{r o}}+\sum_{t=1}^{q_{2}} \frac{s_{t}^{b-}}{b_{r o}}\right)}
$$

$$
\text { s.t. }\left\{\begin{array}{l}
x_{o}=X \lambda+S^{-} \\
y_{o}=Y \lambda-S^{+} \\
b_{o}=B \lambda+S^{b-} \\
\lambda \geq 0, S^{-} \geq 0, S^{+} \geq 0, S^{b-} \geq 0
\end{array}\right.
$$

$$
\text { output, } q_{2} \text { is the undesirable output, } m \text { means the inputs number; } s^{-} \text {is the inputs slacks, }
$$
$s^{+}$is the desirable output slacks, $s^{b-}$ is the undesirable output slacks. $\lambda$ is a nonnegative multiplicative vector of production possibility sets. Equation (1) defines the 
non-radial, non-directional measure of the SBM model. When, this implies that all slack variables are zero and the DMU is undesirable for the output case. Because the objective function is not linear, the available Charnes-Cooper transformation method will optimize the problem to a linear model (Tone, 2001) ${ }^{[45]}$.

$$
\begin{gathered}
\rho=\min \left(t-\frac{1}{M} \sum_{i=1}^{m} \frac{s_{i}^{-}}{x_{i 0}}\right) \\
\text { s.t. }\left\{\begin{array}{l}
1=t+\frac{1}{q_{1}+q_{2}}\left(\sum_{r=1}^{q_{1}} \frac{S_{r}^{+}}{y_{r 0}}+\sum_{j=1}^{q_{2}} \frac{S_{j}^{b-}}{b_{j 0}}\right) \\
t y_{o}=Y \lambda-S^{-} \\
t b_{o}=B \lambda+S^{+} \\
\lambda \geq 0, S^{-} \geq 0, S^{+} \geq 0, S^{b-} \geq 0
\end{array}\right.
\end{gathered}
$$

Using the linear solution model (2), the optimal solution can be obtained. It directly considers the deficiencies of inputs and outputs in the efficiency measure and has the advantage of capturing the entire inefficient aspect, which is suitable for analyzing the efficiency considering non-ideal outputs.

\subsection{Inputs and outputs selection for rescue performance evaluation}

As needed, a list of performance indicators suitable for measuring the performance of geo-hazard relief operations is proposed, either individually or as part of a multiobjective model. These indicators are represented through a framework based on the simplest possible action: input, output, and efficiency indicators. Among them, efficiency indicators refer to the ability to produce the maximum output with the minimum input. Three inputs and two outputs are assumed for a geological disaster relief operation:

$$
\text { efficiency }=\frac{u_{1} \cdot \text { input }_{1}+u_{2} \cdot \text { input }_{2}+u_{3} \cdot \text { input }_{3}}{v_{1} \cdot \text { output }_{1}+v_{2} \cdot \text { output }_{2}}
$$

The inputs and outputs of geological disaster rescue operation performance are sought in Figure 1: the three input factors are rescue teams, rescue time and rescue heavy machinery; the two output outcomes are the number of people affected by the disaster, the total number of people searched and rescued. This model demonstrates the main features of the DEA rescue operation evaluation domain, from which more comprehensive models can be designed. 
Inputs

DMU

Outputs

168
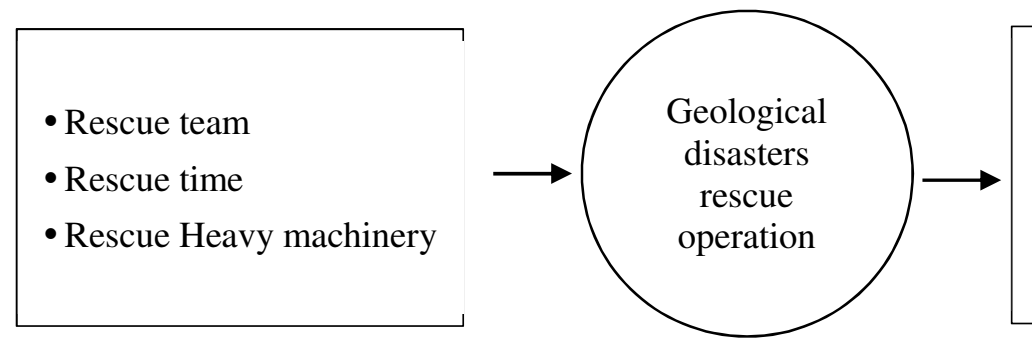

- Relocated people

- Searched and Rescued people

Fig1 Inputs and Outputs of a Geological disasters rescue operation

169

170

171

172

173

174

175

176

177

178

179

180

181

182

183

184

185

186

187

Efficiency is defined as the ratio of output to total input. The concept of effective boundary provides a formal representation of efficiency. Compared with other lowefficiency DMUs, a set of optimal decision-making units (DMUs) are more effective. DMU can represent different geological disaster rescue operations. The efficiency metric can measure the efficiency of the DMU's rescue output given its input (rescue resources).

\subsection{Data collection}

Top 18 worst geological disasters during 2015-2019 in China were selected. Data for each rescue operation is obtained from ministry of emergency management of PRC, https://www.mem.gov.cn/. Table 1 shows a description of the collected data is shown in Table 1.

\section{Table 1}

Descriptive statistics for the collected data.

\begin{tabular}{lcccc}
\hline & Mean & Standard deviation & Minimum & Maximum \\
\hline Rescue team(person) & 5586 & 912.40 & 333 & 39729 \\
Rescue time(day) & 5.83 & 4 & 2 & 18 \\
Rescue Heavy machinery(suit) & 150.83 & 158.93 & 14 & 693 \\
Relocated people(person) & 6211.94 & 11892.41 & 90 & 47200 \\
Searched and Rescued & 28.44 & 26.24 & 0 & 103 \\
people(person) & & & & \\
\hline
\end{tabular}

\section{Empirical Results and Discussion}

\section{1 analysis of the rescue operation performance and performance fluctuations}

The model was run through DEA-Solver software and by calculation, the performance of only 6 out of 18 Geo-hazard rescue operations was effective, where the maximum efficiency score was 1.302 and the minimum 0.413 , with a mean value of 
summarizes the descriptive statistics of the results.

190

Descriptive statistics for DEA results.

193

\begin{tabular}{l|c}
\hline Total number of DMUs & 18 \\
\hline Number of efficient DMUs & 6 \\
\hline Number of inefficient DMUs & 12 \\
\hline Scores average & 0.671 \\
\hline Scores standard deviation & 0.228 \\
\hline Maximum score & 1.302 \\
\hline Minimum score & 0.413 \\
\hline
\end{tabular}

The calculated results show the performance of each rescue operation. Compared with other rescue operations, the efficiency scores of three rescue operations, 2019wc0820, 2018ylzbj1017, 2017gs0807, were greater than 1.0 ranked at the efficiency frontier and can be described as excellent efficiency performance. Table 3 shows the efficiency scores and rankings of the 18 rescue operations.

Table 3

Efficiency scores and ranks of geological disaster rescue operations.

\begin{tabular}{ccccccc}
\hline No. & Year & Location & DMU & Geological disaster & Score & Rank \\
\hline 1 & 2019 & Sichuan & 2019 wc0820 & Debris flow & 1.003 & 3 \\
2 & 2019 & Zhejiang & 2019 zj0810 & Barrier lake & 0.719 & 5 \\
3 & 2019 & Sichuan & 2019 sc0814 & Debris flow & 0.682 & 6 \\
4 & 2019 & Guizhou & 2019 gz0723 & Landslide & 0.602 & 11 \\
5 & 2019 & Shanxi & 2019 sx0315 & Landslide & 0.646 & 8 \\
6 & 2018 & Sichuan & $2018 j s j 1103$ & Landslide & 0.655 & 7 \\
7 & 2018 & Tibet & 2018 ylzbj1017 & Barrier lake & 1.008 & 2 \\
8 & 2018 & Sichuan & $2018 j s j 1011$ & Barrier lake & 0.783 & 4 \\
9 & 2018 & Yunnan & $2018 y n 0902$ & Debris flow & 0.482 & 16 \\
10 & 2018 & Hunan & $2018 \mathrm{hn0630}$ & Landslide & 0.512 & 15 \\
11 & 2017 & Qinghai & $2017 \mathrm{gh0830}$ & Landslide & 0.608 & 9 \\
12 & 2017 & Guizhou & $2017 \mathrm{gz0828}$ & Landslide & 0.602 & 10 \\
13 & 2017 & Gansu & $2017 \mathrm{gs0807}$ & Debris flow & 1.302 & 1 \\
14 & 2017 & Sichuan & 2017 sc0624 & Landslide & 0.527 & 13 \\
15 & 2016 & Zhenjiang & $2016 z j 0928$ & Landslide & 0.514 & 14 \\
16 & 2016 & Fujian & $2016 f j 0508$ & Debris flow & 0.575 & 12 \\
17 & 2015 & Shanxi & 2015 sx0812 & Landslide & 0.446 & 17 \\
18 & 2015 & Zhejiang & $2015 z j 1113$ & Landslide & 0.413 & 18 \\
\hline & & & & & & \\
\hline
\end{tabular}




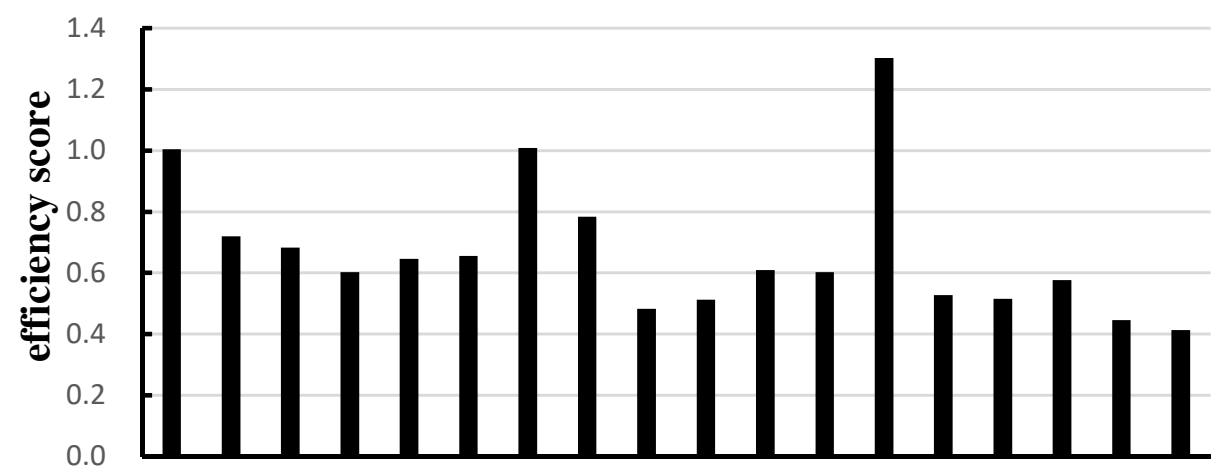

Figure 2 efficiency scores of 18 rescue operations

Figure 2 shows there are 12 rescue operations had lower efficiency scores than the scores average. $67 \%$ of the rescue operations under the average, China's geological disasters rescue system is still at the primary stage, the overall level is not high.

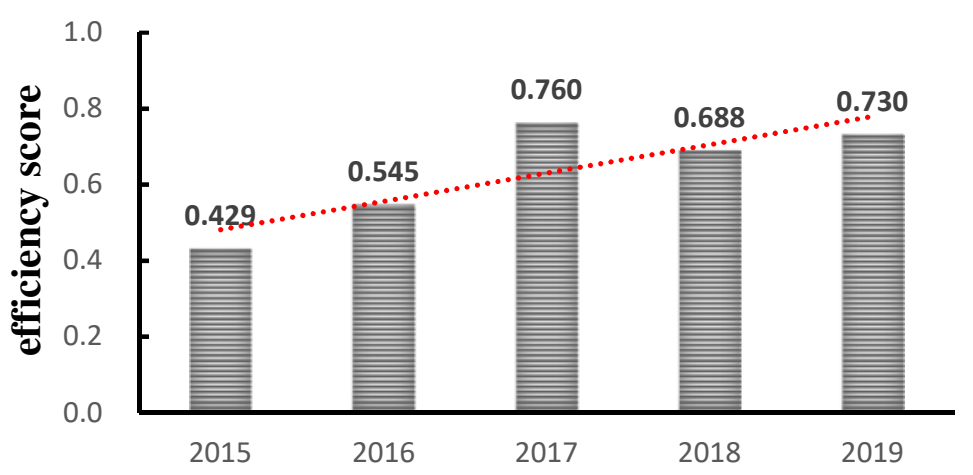

Figure 3 the trend of the geological disaster rescue operation performance 20152019 in China

However, figure 3 shows the efficiency score averages from 2015 to 2019 is continuous improvement. The overall trends in geological disaster rescue performance is getting better and better. Which indicates that China has paid more and more attention to the geological disaster management in recent years. Especially, since the establishment of the Ministry of Emergency Management (MEM) in China, the ability to prevent and resolve major risks and the ability to engage in disaster and disaster relief has been greatly improved since 2019. MEM is very helpful to improve emergency resources and optimize rescue productivity. 


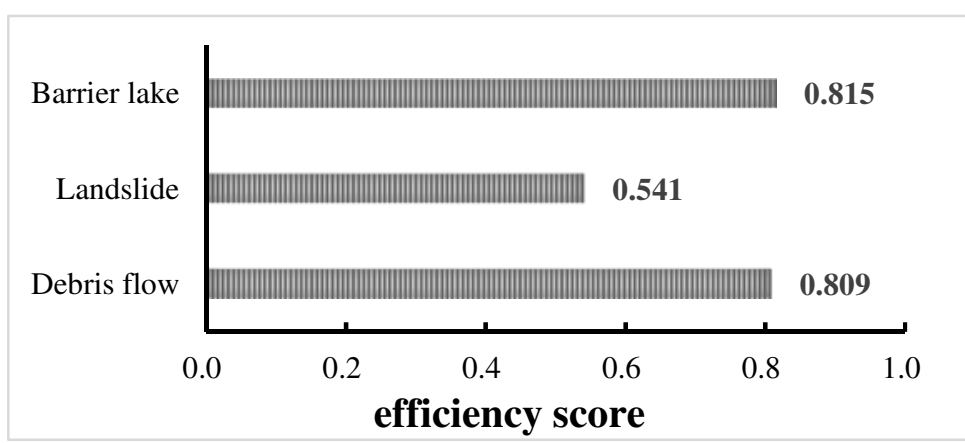

Figure4 the rescue operation efficiency of different geological disasters

Figure4 shows the three rescue operation performance of different types of geological disasters. Barrier lake's rescue operation efficiency average score 0.815 is the largest among the three kinds of geological disasters. Debris flow and Landslide rescue operation efficiency ranked second and third, with their scores of 0.809 and 0.541 , respectively. Landslide search and rescue is the most difficult rescue mission among the three kinds of geological disasters. Landslides are usually classified by type of movement such as sliding, flow, spreading, tipping or falling, and by type of rock, debris or earth material. They usually involve a complex sequence of events - including rotational, translational and flow mechanisms - and are also referred to as debris-avalanche flows. Sometimes there are more than one type of movement, and the temporal and spatial relationships of the movements can be complex. made it more difficult for heavy machinery to get to the rescue site. so, landslide rescue operation is more dangerous and complex than other geological disaster rescue, which decreases the rescue operation efficiency. In the future, China should put priority on improving its landslide search and rescue capacity.

\subsection{Factors influencing geological disaster rescue operation performance}

The variables $s_{j}^{-}$and $s_{k}^{+}$are called slacks, because they indicate lack of performance.

239 For example, although DMUA completely controls a point with $\left(x_{1}^{\prime}, x_{2}^{\prime}, x_{3}^{\prime}, y_{1}^{\prime}, y_{2}^{\prime}\right)$ as the coordinate, this can be interpreted by $\left(s_{1}^{-}, s_{2}^{-}, s_{3}^{-}, s_{1}^{+}, s_{2}^{+}\right)$, compared with the 
performance of DMUA, the performance at this point is insufficient. Based on the effective frontier.

246 Table 4 Summary of input and output slacks

\begin{tabular}{|c|c|c|c|c|c|c|c|c|c|c|}
\hline \multirow{3}{*}{$\begin{array}{c}\text { DMU } \\
19 \mathrm{wc} 0820\end{array}$} & \multirow{3}{*}{$\begin{array}{l}\text { Score } \\
1.003\end{array}$} & \multicolumn{6}{|c|}{ Inputs } & \multicolumn{3}{|c|}{ Outputs } \\
\hline & & \multicolumn{2}{|c|}{$\overline{S_{1}^{-}}$} & \multicolumn{2}{|c|}{$S_{2}^{-}$} & \multicolumn{2}{|c|}{$S_{3}^{-}$} & \multicolumn{2}{|c|}{$S_{1}^{+}$} & \multirow{2}{*}{$\frac{S^{b}}{0}$} \\
\hline & & 0.077 & $0.96 \%$ & 0.000 & $0.00 \%$ & 0.000 & $0.00 \%$ & 0.000 & $0.00 \%$ & \\
\hline 2019zj0810 & 0.719 & 0.348 & $-4.27 \%$ & 0.602 & $-43.45 \%$ & 0.000 & $0.00 \%$ & 1.506 & $16.94 \%$ & 0 \\
\hline 2019sc0814 & 0.682 & 0.000 & $0.00 \%$ & 2.080 & $-71.95 \%$ & 0.608 & $-10.67 \%$ & 0.630 & $6.22 \%$ & 0 \\
\hline 2019gz0723 & 0.602 & 0.000 & $0.00 \%$ & 0.704 & $-50.76 \%$ & 0.419 & $-8.90 \%$ & 2.254 & $33.14 \%$ & 0 \\
\hline 2019sx0315 & 0.646 & 0.326 & $-5.10 \%$ & 1.183 & $-66.00 \%$ & 0.000 & $0.00 \%$ & 1.244 & $18.19 \%$ & 0 \\
\hline 2018jsj1103 & 0.655 & 1.957 & $-21.25 \%$ & 1.575 & $-68.39 \%$ & 0.000 & $0.00 \%$ & 0.633 & $7.02 \%$ & 0 \\
\hline 2018ylzbj1017 & 1.008 & 0.000 & $0.00 \%$ & 0.000 & $0.00 \%$ & 0.087 & $2.40 \%$ & 0.000 & $0.00 \%$ & 0 \\
\hline 2018jsj1011 & 0.783 & 2.357 & $-28.45 \%$ & 0.098 & $-14.21 \%$ & 0.000 & $0.00 \%$ & 0.692 & $9.61 \%$ & 0 \\
\hline 2018yn0902 & 0.482 & 0.219 & $-2.07 \%$ & 0.346 & $-24.93 \%$ & 0.000 & $0.00 \%$ & 6.495 & $88.81 \%$ & 0 \\
\hline 2018hn0630 & 0.512 & 0.000 & $0.00 \%$ & 0.516 & $-46.95 \%$ & 0.121 & $-3.20 \%$ & 2.979 & $62.68 \%$ & 0 \\
\hline 2017qh0830 & 0.608 & 3.017 & $-47.17 \%$ & 0.354 & $-51.07 \%$ & 0.507 & $-19.23 \%$ & 0.000 & $0.00 \%$ & 0 \\
\hline $2017 \mathrm{gz} 0828$ & 0.602 & 1.496 & $-19.69 \%$ & 1.467 & $-70.54 \%$ & 0.000 & $0.00 \%$ & 1.125 & $16.06 \%$ & 0 \\
\hline $2017 \mathrm{gs} 0807$ & 1.302 & 2.747 & $39.77 \%$ & 0.115 & $16.56 \%$ & 0.000 & $0.00 \%$ & 0.807 & $-8.77 \%$ & 0 \\
\hline $2017 \operatorname{sc} 0624$ & 0.527 & 0.000 & $0.00 \%$ & 0.381 & $-34.68 \%$ & 0.763 & $-14.46 \%$ & 3.518 & $58.59 \%$ & 0 \\
\hline 2016zj0928 & 0.514 & 0.950 & $-10.35 \%$ & 1.120 & $-57.54 \%$ & 0.000 & $0.00 \%$ & 3.676 & $50.45 \%$ & 0 \\
\hline 2016fj0508 & 0.575 & 0.382 & $-4.16 \%$ & 0.725 & $-45.03 \%$ & 0.000 & $0.00 \%$ & 3.659 & $45.29 \%$ & 0 \\
\hline $2015 \mathrm{sx} 0812$ & 0.446 & 0.736 & $-10.38 \%$ & 1.665 & $-72.31 \%$ & 0.000 & $0.00 \%$ & 3.256 & $62.56 \%$ & 0 \\
\hline 2015zj1113 & 0.413 & 0.000 & $0.00 \%$ & 1.250 & $-60.10 \%$ & 0.032 & $-0.61 \%$ & 5.305 & $93.01 \%$ & 0 \\
\hline
\end{tabular}

Table 4 show the input and output slacks of geological disaster rescue operations.

248 The DEA analysis of relative efficiency provides useful information on the strengths 249 and weaknesses of each DMU and contributes to the improvement of the efficiency 250 level of the "best" DMUS. The main reasons which caused the inefficiency of the rescue 251 operations include overreaction and shortage of in professional rescue facilities. 252 China's political system and its pattern of crisis management are different from western 253 countries. China's government has strong capacity of mass mobilization in short time 254 when crisis outbreaks. However, one of the most common things we've noticed is the 255 government always overreacting to the disasters. From the table 4 , we can see the 
inefficient rescue operations have the problem of resource redundancy. About 20\%-30\%

rescue team and $30 \%$ rescue time can be reduced. Besides, about $15 \%$ rescue heavy

machinery can be reduced. In geological disaster rescue operation, most rescue sites are limited and confined, though many heavy rescue machinery are deployed, only several can work at the same time.

\subsection{Policy implications aiming at improving geo-disaster rescue performance}

For the purpose of improvement of Geological disaster rescue efficiency in China, the flowing suggestions can be provided:

(1)Search and rescue techniques and standards on geological disasters should be developed to support the emergency rescue operations. China can dispatch sufficient rescue teams to the impact areas after geological disasters happened. However, the rescue techniques of the rescuers in geological disasters are still inadequate. China has established special standards and methodology for earthquake rescue operations which making humanitarian coordination and response more effective, timely, and coherent. There are no standards in geological disaster search and rescue in China. Experts should be bring together to share knowledge and develop standards to strength the effectiveness and Coordination of rescue operation in geological disasters. As the government authority, the Ministry of Emergency Management should establish minimum standards and procedures for special rescue teams, as well as training, preparation, classification and operational specifications for emergency rescue, and provide guidance on geological disaster search and rescue methods.

(2) Multifunctional integrated rescue machinery should be designed for geological disaster search and rescue. Construction machinery such as excavator and dump truck, have become one of the most important rescue equipment for debris removing and road rehabilitation in geological disaster search and rescue. Generally, several kinds of construction machinery should work together in the disaster field. But most workspaces are confined and limited. Only one construction machinery operate onsite while others waiting outside. The working efficiency of construction machinery are very low. So, 
geological disaster search and rescue. Quick grab-pass and Multi-purpose wheeled vehicle will significant increase search and rescue efficiency.

(3) In China, there should be greater coordination between the various individual, state, county, provincial and national agencies involved in geological disaster relief operations.

In the giant debris flow disaster which caused more than 1700 casualties in Zhouqu county, Gansu province at 2010, there are more than 9 relief headquarters in the disaster field. The staffs of the headquarters comes from different departments including central government, local government, military, police, enterprises. Different agencies initiated different emergency response level from their own views, which led to disorder and confusion in the early response. After a disaster, a rapid, coordinated and effective response not only minimizes the loss of life and property, but also promotes early recovery. Agencies and functions must have a clear understanding of their respective roles, responsibilities, and specific actions that must be taken. Coordination and synergy between agencies at all levels is enhanced through standard operating procedure setting, information system sharing, and coordination mechanism establishment.

\section{Conclusions}

In this study, SBM-DEA is used as a possibility to evaluate geohazard methods from the perspective of rescue operation efficiency. The advantages and disadvantages of the geohazard rescue operation efficiency perspective are analyzed, and possible directions for improvement are proposed. SBM-DEA analysis scores of geological disaster rescue operation performance on a scale of 0 -1.4.The analysis identifies rescue operations 2019wc0820, 2018ylzbj1017, and 2017gs0807 as efficient frontier units. Compared to the rest of the rescue operations, these three rescue operations are relative efficient, which serve as the benchmark for the disaster emergency response. These three efficient rescue operations can be utilized as role models, from which lessons and experiences can be learned in order to improve the future geological disaster rescue operation 
efficiency.

After identifying several factors that drive the performance of disaster relief operations for disaster management studies, the SBM-DEA model was used to analyze and derive relevant and valid information. Due to the data collection date, only three input variables and two output variables were considered as a case study, and the range of optional variables could be further increased to be more extensive in further studies. An attempt was made to correlate the variability of rescue operation performance with certain explanatory variables to verify the consistency of the study findings.

Acknowledgements: This paper is supported by the National Social Science Foundation of China ( 17BGL176).

Ethical Statement: I certify that this manuscript is original and has not been published and will not be submitted elsewhere for publication while being considered. And the study is not split up into several parts to increase the quantity of submissions and submitted to various journals or to one journal over time. No data have been fabricated or manipulated (including images) to support your conclusions. No data, text, or theories by others are presented as if they were our own.

The submission has been received explicitly from all co-authors. And authors whose names appear on the submission have contributed sufficiently to the scientific work and therefore share collective responsibility and accountability for the results.

Conflict of Interest: The authors declare that they have no conflict of interest. This article does not contain any studies with human participants or animals performed by any of the authors. Informed consent was obtained from all individual participants included in the study.

\section{Reference}

[1] EM-DAT. EM-DAT Data Entry Procedures [EB OL]. [2020-10-30). https://www.emdat.be/database

[2] Wang X., Zhou H. Progress and prospect of statistics and assessment of large-scale natural disaster damage and losses [J]. Advances in Earth Science, 2018, 33(9): 914-921.

[3] Fang L., Xia Y., Yang Y., et al. The literature review and future prospects of relief supply chain for unexpected natural disasters [J]. Management Review, 2016, 

28(08):238-249.

[4] Dong B., Zhang Z., Xu L., et al. Research status and development trend of intelligent emergency rescue equipment [J]. Journal of Mechanical Engineering, 2020, 56(11):13-37.

[5] Fu Y., Wang J. Application of geological disaster risk management performance evaluation system based on the BSC [J]. International Business and Management. 2015, 10(1):50-54.

[6] Charnes A., Cooper W.W., Rhodes E. Measuring the efficiency of decision making units[J]. European Journal of Operational Research, 1978, 2: 429-444.

[7] Cooka W D. Data Envelopment Analysis (DEA) - Thirty years on[J]. European Journal of Operational Research, 2009, 192(1):1-17.

[8] Golany B, Roll Y. An application procedure for DEA[J]. Omega, 1989, 17(3):237250.

[9] Bessent A., Bessent W., Kennington J., et al. An application of mathematical programming to assess productivity in the Houston independent school district[J]. Management Science. 28 (1982) 1355-1367.

[10] Thanassoulis E. Data envelopment analysis and its use in banking[J]. Interfaces, 1999, 29(3):1-13.

[11] Ebrahimnejad A, Tavana M, Lotfi F H , et al. A three-stage Data Envelopment Analysis model with application to banking industry[J]. Measurement, 2014, 49:308-319.

[12] Wahab M I M, Wu D, Lee C G. A generic approach to measuring the machine flexibility of manufacturing systems[J]. European Journal of Operational Research, 2008, 186(1):137-149.

[13] Xu J, Li B, Wu D. Rough data envelopment analysis and its application to supply chain performance evaluation[J]. International Journal of Production Economics, 2009, 122(2):628-638.

[14] Cooper W W, Park K S, Yu G. An Illustrative Application of Idea (Imprecise Data Envelopment Analysis) to a Korean Mobile Telecommunication Company[J]. Operations Research, 2001, 49(6):807-820.

[15] Jacobs R. Alternative methods to examine hospital efficiency: data envelopment analysis and stochastic frontier analysis[J]. Health Care Management Science. 2001 (4): 103-115.

[16] Cooper W W, José L. Ruiz, Sirvent I. Selecting non-zero weights to evaluate effectiveness of basketball players with DEA[J]. European Journal of Operational Research, 2009, 195(2):563-574.

[17] Sexton T R, Lewis H F. Two-Stage DEA: An Application to Major League Baseball[J]. Journal of Productivity Analysis, 2003, 19(2/3):227-249.

[18] Abdullah B, Aldamak A, and S. Z. A. Review of efficiency ranking methods in data envelopment analysis[J]. Measurement, 2017, 106:161-172.

[19] Deng Z, Huang S, Zhu G. Temporal and spatial distribution characteristics analysis for fujian landslide disasters based on disaster data in recent five years [J]. Journal of Geological Hazardsand Environment Preservation, 2019, 30(04):17-23.

[20] Chen C. Study on the Mechanism of the Impact of Heavy Rain and High Temperature Weather on Geological Disasters [J]. Journal of Catastrophology, 2020, 35(01):32-37.

[21] Zhou J, Zhao F, Li H, et al. Correlational Research between Geological Hazards and impact Factors in Shaanxi Province [J]. Journal of Catastrophology, 2019, 

34(02):228-234.

[22] Hong Z, Li Y, Zhang L, et al. A Method of Regional Geological Hazard Assessment Based on Principle Component Analysis [J]. Journal of Catastrophology, 2020, 35(01):118-124.

[23] Wang G, Ye Z, Li G, et al. Geological Hazard Risk Assessment of Zhouqu County in Bailong River Basin[J]. Journal of Catastrophology, 2019, 34(03):128-133.

[24] He S, Jiang Y, Ji X. A Review of Studies on Economic Losses Caused by Debris Flow Disasters [J].Journal of Catastrophology, 2019, 34(04):153-158.

[25] Niu H. Prediction of Landslide Geological Hazards in Soil-rock Contact Zone in Southern Shaanxi [J]. Journal of Catastrophology, 2020, 35(01):125-130.

[26] Wang J. Design of Mine Geological Hazard Index System Based on Multi-level Fuzzy Mathematics [J]. Journal of Catastrophology, 2019, 34(04):14-18.

[27] Meesters K, Van d W B A. Increasing efficiency of humanitarian organizations with volunteer driven information products[C]. 2014. 47th Hawaii International Conference on System Sciences (HICSS). IEEE 2014:149-158

[28] Balcik B, Beamon B M. Facility location in humanitarian relief[J]. International Journal of Logistics Research and Applications, 2008, 11(2):101-121.

[29] Wei J, Zhao D, Marinova D. Disaster Relief Drivers: China and the US in Comparative Perspective[J]. China an International Journal, 2013, 11(2):93-116.

[30] Wei J, Marinova D. The orientation of disaster donations: differences in the global response to five major earthquakes[J]. Disasters, 2016, 40(3): 452-475.

[31] Gao L, Wu Q, Li Y, et al. How Prepared Are Hospitals' Emergency Management Capacity? Factors Influencing Efficiency of Disaster Rescue[J]. Disaster Medicine \& Public Health Preparedness, 2018, 12(2): 176-183.

[32] Acimovic J, Goentzel J. Models and metrics to assess humanitarian response capacity[J]. Journal of Operations Management, 2016, 45:11-29.

[33] Sun H, Zhao J, Liu T, et al. Research on the Efficiency Evaluation of Emergency Medical Rescue Process after Earthquake [J]. Chinese Journal of Management Science, 2019, 27(01):205-216.

[34] Zobel C W, Altay N, Haselkorn M P. Advances in Managing Humanitarian Operations[M]. Springer International Publishing, 2016.

[35] Abidi H, de Leeuw S, Klumpp M. Humanitarian supply chain performance management: a systematic literature review[J]. Supply Chain Management: An International Journal, 2014, 19(5/6):592-608.

[36] Blecken A. Supply chain process modelling for humanitarian organizations[J]. International Journal of Physical Distribution \& Logistics Management, 2010, 40(8-9): 675-692.

[37] Schulz S F, Heigh I. Logistics performance management in action within a humanitarian organization[J]. Management Research News, 2009, 32(11):10381049.

[38] Üstün A K, Barbarosoğlu G. Performance evaluation of Turkish disaster relief management system in 1999 earthquakes using data envelopment analysis[J]. Natural Hazards, 2015, 75(2): 1977-1996.

[39] Guan G. Research on the Collaboration Mechanism of Humanitarian relief Supply Chain [D]. Chang' an University, 2016.

[40] Leng Q. The Evaluation and Analysis of Natural Disaster Relief Efficiency of 

Technology of China, 2018.

440 [41] Lin W, Wang N. A comparison study on the rescue efficiency in the international waters: a case of the specific waters in the East China Sea [J]. Marine Science Bulletin, 2019, 38(04):438-446.

[42] Liu Y, Wei J, Xu J, et al. Evaluation of the moderate earthquake resilience of 91(2): 587-609.

[43] Mujasi P N, Asbu E Z, Puig-Junoy J. How efficient are referral hospitals in Uganda? A data envelopment analysis and Tobit regression approach[J]. BMC health services research, 2016, 16(1): 230.

[44] Neralić, Luka. Sensitivity in Data Envelopment Analysis for Arbitrary Perturbations of All Data in the Charnes-Cooper-Rhodes Model[J]. Parametric Optimization \& Related Topics V, 2000:143-163.

[45] Tone K. A slacks-based measure of efficiency in data envelopment analysis[J]. European Journal of Operational Research. 2001(130) 498-509. Analysis. Springer US, 2011. 